\title{
Insight on the inhibitive property of potassium ion on the stability of shale: a diffuse double-layer thickness $\left(\kappa^{-1}\right)$ perspective
}

\author{
Talal AL-Bazali ${ }^{1}$ (1)
}

Received: 10 May 2021 / Accepted: 14 June 2021 / Published online: 18 June 2021

(c) The Author(s) 2021

\begin{abstract}
It is believed that potassium ions reduce the hydration energy and swelling of clays and thus promoting stability to shales. This belief was made based on volumetric and linear expansion data obtained from shale and $\mathrm{KCl}$ solutions interactions. However, swelling data alone is not adequate to mitigate wellbore instability in shale. Such data must be incorporated with mechanical and physicochemical data for complete and accurate wellbore instability analysis.

This paper presents clear experimental evidence showing that concentrated potassium chloride solutions tend to suppress shale swelling as higher concentration of potassium ions collapses the diffuse double layer of clay particles causing shale shrinkage which confirms the notion that the Debye length $\left(\kappa^{-1}\right)$ decreases as the ionic concentration increases.

Results show that there exists a $\mathrm{KCl}$ concentration threshold above which shale's compressive strength deteriorates significantly. This concentration threshold was found to hover around $5 \%$ by weight. The amount of water and ions uptake into shale was quantified using gravimetric measurements. Significant potassium ions invasion into shale was experimentally measured as $\mathrm{KCl}$ solution concentration increased which proved the leaky nature of shale's membrane. The reduction of shale's compressive strength seems to be well correlated with the amount of ions uptake into shale. Moreover, data suggests that shale's compressive strength was not significantly impacted by swelling. It was possible to gravimetrically separate osmotic water from associated water as shale interacted with $\mathrm{KCl}$ solutions. Results suggest that osmotic water is responsible for shale swelling since it is unattached to ions which makes it free to move around inside shale. On the other hand, data suggest that associated water does not contribute to shale swelling as it is bound to potassium ions which makes it unfree to move around. It is fair to state, based on our experimental data, that osmotic water is responsible for shale swelling while associated water contributes to shale's compressive strength alteration.
\end{abstract}

Keywords Shale stability · Potassium ion · Diffuse double layer · Debye-Hückel length · Osmotic pressure · Associated water $\cdot$ Uniaxial compressive strength $\cdot$ Van der Waals force

\section{Background and prior work}

Ultra-low permeability, negatively charged surface and high clay content distinguish shale from other sedimentary rocks. Their tiny pore throat diameters which range from 3 to $100 \mathrm{~nm}$ coupled with their negatively charged clay surfaces create a favorable environment for water and ions exchange when exposed to aqueous solutions (Bybee 2009). Shale acquires its negative charge through a process

Talal AL-Bazali

albazali1972@outlook.com

1 Kuwait University, Kuwait City, Kuwait known as isomorphous substitution where one structural cation replaces another of similar size but different valent charge creating a surface charge deficiency. This replacement represents the primary source of both negative and positive charges in clay minerals. For example, the substitution of one $\mathrm{Al}^{3+}$ for a $\mathrm{Si}^{4+}$ in the tetrahedron yields an excess of one negative charge. Clay minerals exhibit substitutions that cause both positive and negative charges. The number of electrons lost and gained by isomorphous substitution within the clay mineral structure determines its net charge. The existence of negative charges on clay surfaces enables shale to adsorb water which could lead to shale swelling and strength reduction (Santarelli and Carminati 1995). Lomba et al. (2000) stated that these negative charges facilitate 
the transport of cations and prevent the transport of anions which could impact swelling properties and mechanical integrity of shale. The low permeability of shale together with their affinity to adsorb water promoted by the existence of negatively charged clay surfaces made shale very susceptible to the development of swelling and hydrational stresses and loss of mechanical cohesive strength.

Clay swelling can be divided into two categories: intercrystalline swelling and osmotic swelling. Inter-crystalline swelling results from hydration of exchangeable cations of dry clay while osmotic swelling is caused by ionic concentrations imbalances between clay surface and aqueous solutions. According to Madsen and Müller-Vonmoos (1989), the swelling behavior of clay rocks depends on the type and quantity of clay minerals encountered, their surface charge and the valence of the cations in the diffuse double layer. Diffuse double layer is an ionic structure that defines the variation of electric potential near charged clay surfaces and has a significant effect on the behavior of colloidal particles such as clay when they come in contact with aqueous solutions as shown in Fig. 1.

Wellbore instability problems have mainly been credited to the adverse interaction between shale and aqueous phase of drilling fluids. The direct interaction between water in drilling fluid and shale's pore fluid permits the exchange of water between shale and drilling fluids particularly when the water activity of shale is different from that of drilling fluid. This could cause shale swelling, hydrational stresses, strength reduction all of which could lead to shale failure and collapse (AL-Bazali et al. 2008). It is estimated that wellbore instability problems cost the oil and gas industry over one billion dollars annually (Dzialowski et al. 1993). Therefore, efforts and resources were directed to solve such problems by osmotically stopping the exchange of water between shale and drilling fluids under the assumption that shale acts as a perfect semi-permeable membrane. When two solutions of different concentrations are separated by a semipermeable membrane, as shown in Fig. 2, an osmotic pressure develops and promotes water transport from the lower ionic concentration region to the higher ionic concentration region. The magnitude of osmotic pressure is given by:

$p=\left(R T / V_{w}\right) \ln \left(a_{w 1} / a_{w 2}\right)$

where $R$ is the gas constant, $T$ is the absolute temperature, $V_{w}$ is the partial molar volume of water and $a_{w 1}$ and $a_{w 2}$ are the water activities of the shale's pore fluid and salt solution, respectively.

Exploiting the concept of osmosis was encouraged by many researchers to limit the transfer of water into shale. It is believed that extracting water out of shale could strengthen shale and enhance its cohesive strength (Chenevert 1969). In the absence of a hydraulic pressure gradient, the flow of water into shale is mainly controlled

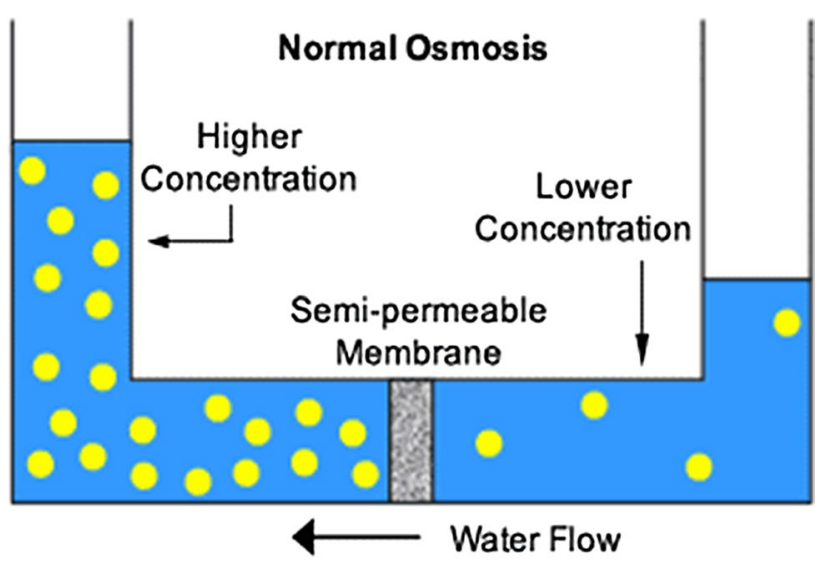

Fig. 2 The concept of osmosis
Fig. 1 Diffuse double layer of clay showing the distribution of cations \& anions adjacent to negative clay surface
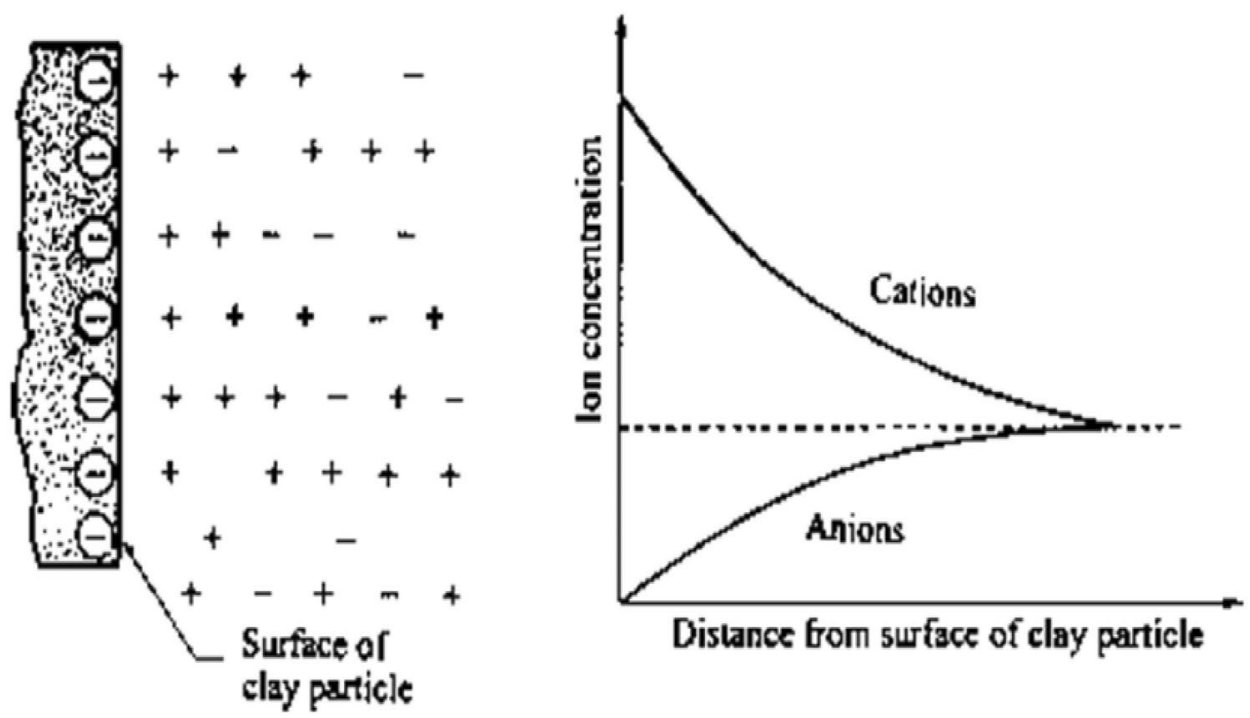
by the chemical potential imbalance between shale's pore fluid and drilling fluid (Ewy and Stankovich 2000). Based on this scientific notion, recommendations for best drilling practices focused on using low water activity drilling fluids when drilling shales in order to osmotically extract water out of shale in order to avoid its swelling and strength reduction. Lowering the water activity of drilling fluids necessitates the addition of salts to drilling fluids so that its chemical potential is lower than that of shale. While the addition of salts could promote water flow out of shale by osmotic means, it also results in ionic diffusion into shale owing to the imposed ionic concentration imbalance between shale and drilling fluid. Ions transferred into shale are accompanied by their associated water "known as water cloud," as shown in Fig. 3, by means of diffusion osmosis. The diffusion of ions and their associated water is controlled by a concentration gradient that is given by Fick's law:

$J=-D_{i} *\left(C_{i 1}-C_{i 2}\right) / D L$

where $J$ is mass flux of ith ion; $D_{i}$ the diffusion coefficient of the ith ion; $C_{i l}$ is the concentration of ith ion in shale's pore fluid; $C_{i 2}$ is the concentration of ith ion in salt solution and $\delta L$ is shale's length.

The flow of ions and their associated water could totally negate the beneficial impact of osmotically drawing water out of shale. It has been shown by many researchers that the transfer of ions and their associated water into shale could change the shale's pore fluid make up, cause cementation bonds dissolution, reduce friction between grains, decrease shale's compressive strength and young modulus and ultimately lead to shale failure (Fam and Dusseault 1998 and Simpson and Dearing 2000). Table 1 shows

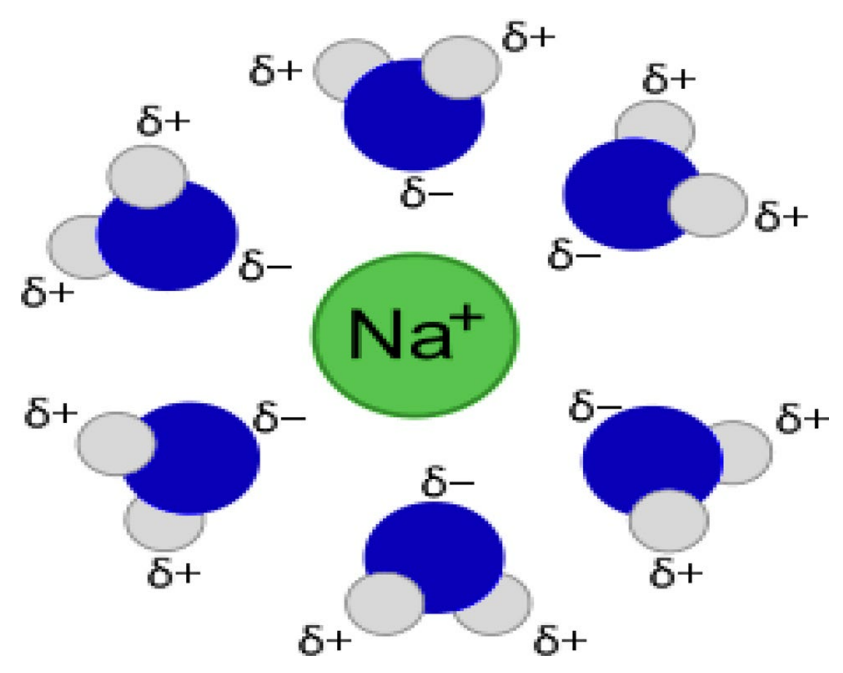

Fig. 3 Sodium ion and its associated water "water cloud",
Table 1 Hydrated ion size compared to their bare ion size for several ions

\begin{tabular}{lll}
\hline Ion Type & Ionic Radius $(\AA)$ & $\begin{array}{l}\text { Hydrated } \\
\text { Ionic Radius } \\
(\AA)\end{array}$ \\
\hline $\mathrm{K}^{+}$ & 1.38 & 3.31 \\
$\mathrm{Na}^{+}$ & 1.02 & 3.58 \\
$\mathrm{Ca}^{+2}$ & 1.00 & 4.12 \\
$\mathrm{Mg}^{+2}$ & 0.72 & 4.28 \\
$\mathrm{Cl}^{-}$ & 1.81 & 3.32 \\
\hline
\end{tabular}

hydrated ions sizes in comparison with their bare "unhydrated" sizes for several ions.

It is argued that some ions especially potassium ions have less detrimental impact on shale swelling and mechanical properties than others such as sodium and calcium ions (Zhang et al. 2016; Tao et al. 2010; Meng et al. 2020; Denis et al. 1991; Van Oort 2003). Therefore, many operators have adopted the use of potassium chloride to solve shale instability problems especially those related to shale swelling and hydration. Mondshine (1973) developed a polymer-based potassium mud that minimizes osmotic hydration and suppresses clay swelling. His work ignored the adverse effects of potassium ion on the mechanical strength of shale. Lu (1988) argued, based on swelling measurements, that potassium ions can replace sodium ions in a sodium montmorillonite shale through cationic exchange and result in a tight, hard shale. Naeimavi et al. (2021) reported that potassium-based drilling fluids can stabilize water-sensitive shale formations and exhibit better rheology and less filtration volume. Shi et al. (2019) showed that the swelling potential of shale decreased with increasing $\mathrm{KCl}$ concentration. In addition, they showed that $\mathrm{KCl}$ exhibited a certain inhibitory effect on the weakening of the mechanical properties of samples where an increase in the $\mathrm{KCl}$ concentration increases the compressive strength and elastic modulus, and decreases the Poisson's ratio. Using linear swelling tests, Cao et al. (2018) showed that $\mathrm{K}_{2} \mathrm{SiO}_{3}$ inhibits clay hydration far better than other inorganic shale inhibitors.

When potassium ion interacts with shale, it impacts its swelling tendency and at the same time alters its mechanical properties. While many studies have focused on the benefits of potassium ions in reducing shale swelling, the impact of potassium ions on the mechanical properties of shale has been largely ignored. The adverse effect of potassium ion on shale strength could far exceed its positive impact on shale swelling. Therefore, one cannot rely on positive swelling data to validate the use of potassium ions without a complete understanding of the impact of potassium ion on the shale's mechanical strength. I believe that a complete assessment of the impact of potassium ions on shale swelling and

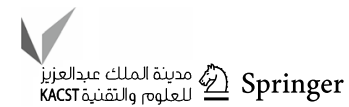


mechanical strength must be done concurrently to better understand the inhibitive role of potassium ion.

In this work, I have performed sets of experiments that integrate the impact of potassium ion on shale's physicochemical and mechanical properties. A complete swelling, compressive strength and ions and water exchange experiments were concurrently performed on the same shale cores so that all results could be combined and analyzed to give an accurate evaluation of the role of potassium ion in stabilizing shale. In addition, understanding the impact of potassium ion concentration on the diffuse double-layer thickness could provide valuable information regarding the inhibitive behavior of potassium ions on shale swelling.

\section{Shale cores and properties}

Two shale cores were utilized in this investigation: shale (A) and shale (B). Shale cores were donated by a Kuwaiti oil company. These cores were taken from Ghar formation located in Mesopotamian geosyncline sedimentary basin. Safety measures were taken to lessen interaction of shale cores with air during coring, handling, storing, and transporting. When received, shale cores were fully covered in a thick polyethylene bag and were kept inside a closed barrel for protection purposes. Upon arrival at our laboratory, shale cores were taken out of the closed barrel and immersed in storage cans full of mineral oil and sealed tightly. The

Table 2 The mineralogical composition of shales (A and B)

\begin{tabular}{lcc}
\hline X-Ray diffraction & Shale (A) \% by weight & $\begin{array}{l}\text { Shale (B) } \% \\
\text { by weight }\end{array}$ \\
\hline Quartz & 17.5 & 15.2 \\
Feldspar & 6.2 & 4.1 \\
Calcite & 3.2 & 1.7 \\
Dolomite & 7.5 & 1.8 \\
Pyrite & 2.7 & 1.4 \\
Siderite & 1.6 & 1.5 \\
Total Clay & 61.3 & 74.3 \\
Chlorite & 3.9 & 3.5 \\
Kaolinite & 7.09 & 6.8 \\
Illite & 11.2 & 7.49 \\
Smectite & 13.7 & 22.4 \\
Mixed Layer & 25.39 & 34.18 \\
\hline
\end{tabular}

mineralogical compositions of shales (A) and (B) are shown in Table 2 while their petrophysical and chemical properties are shown in Table 3. Methods for obtaining mineralogical composition, water content, water activity, cation exchange capacity, porosity and permeability of shales (A) and (B) are described next.

\section{Mineralogical Composition Characterization}

X-Ray diffraction (XRD) was utilized to identify the crystalline structure and composition of shale minerals by determining the angles at which the X-Ray beam is diffracted (Breeden and Shipman 2004). The wavelength for an X-Ray is of the range of 0.01 to $100 \AA$. Because the spacing of atomic planes in crystalline materials is in the order of about $1 \AA$ Á, this makes X-Rays a useful tool in investigating crystalline structure and mineralogical composition of shale. In this work, X-Ray diffraction was performed by an independent commercial laboratory located in Houston, Texas.

\section{Water content $\left(\boldsymbol{W}_{\boldsymbol{c}}\right)$ determination}

Water content $\left(\boldsymbol{W}_{\boldsymbol{c}}\right)$ of shale was determined as follows:

- Cubical shale samples $(1 ', \times 1$ ', $\times 1$ '’) were cut from the well-preserved shale core using a well l-lubricated electrical saw. Mineral oil was used for lubrication and cooling purposes.

- Samples were cleaned using a nontoxic commercial hexane and weighted to obtain their initial weight $\left(W_{1}\right)$.

- Samples were then dried in an oven at $200^{\circ} \mathrm{F}$ for $24 \mathrm{~h}$ to obtain their dry weight $\left(W_{2}\right)$. Drying shale at $200^{\circ} \mathrm{F}$ temperature appears to be adequate for liberating the "free" water without disturbing the clay bound water (Chenevert and Amanullah 1997).

- The water content of shale can be calculated using the following equation:

$$
W_{c} \%=100\left(\frac{W_{1}-W_{2}}{W_{1}}\right)
$$

Using the above experimental procedure, the water contents of shales A and B were measured to be 6.5 and $10.09 \%$, respectively.
Table 3 The petrophysical and chemical properties of shales (A) and (B)

\begin{tabular}{lcllllc}
\hline Property & $\begin{array}{l}\text { Water con- } \\
\text { tent }(\%)\end{array}$ & Water activity & Porosity $(\%)$ & $\begin{array}{l}\text { Permeabil- } \\
\text { ity (nD) }\end{array}$ & $\begin{array}{l}\text { CEC, ml. } \\
\text { eq/100 gm }\end{array}$ & Burial depth (feet) \\
\hline Shale (A) & 6.5 & 0.92 & 7.9 & 1.3 & 17.9 & 15,890 \\
Shale (B) & 10.09 & 0.96 & 12.8 & 3.7 & 24.7 & 8,310 \\
\hline
\end{tabular}




\section{Water activity $\left(a_{w}\right)$ determination}

Adsorption isotherm tests were used to determine the native water activity of shale. The adsorption isotherm curve is established by plotting water absorbed by shale when placed in various desiccators versus the desiccator relative humidity. Different kinds of saturated salt solutions were used to maintain various relative humidity environments. Table 4 shows the employed saturated salts and their corresponding relative humidity values. Full description of the adsorption isotherm methodology can be found elsewhere (Zhang et al. 2004). The water activity of shale A was estimated to be 0.92 corresponding to its $6.5 \%$ water content while the water activity of shale B was estimated to be 0.96 corresponding to its $10.09 \%$ water content.

Table 4 Saturated salts and their respective relative humidity

\begin{tabular}{ll}
\hline Saturated Salt & $\begin{array}{l}\text { Relative } \\
\text { Humidity } \\
(\%)\end{array}$ \\
\hline $\mathrm{K} 2 \mathrm{SO} 4$ & 98 \\
$\mathrm{KNO} 3$ & 94 \\
$\mathrm{KCl}$ & 86 \\
$\mathrm{NaCl}$ & 76 \\
$\mathrm{Ca}(\mathrm{NO} 3) 2$ & 50 \\
$\mathrm{CaCl} 2$ & 30 \\
$\mathrm{ZnCl} 2$ & 10 \\
\hline
\end{tabular}

\section{Cation exchange capacity determination}

Cation exchange capacity of shale was determined following standard procedure for Methylene Blue Index of Clay as per ASTM (American Society for Testing and Materials 1988). This procedure relies on the linear relationship between the methylene blue index and cation exchange capacity (CEC). The procedural steps are as follows:

- Place $2 \mathrm{~g}$ of grounded shale in a $600-\mathrm{mL}$ beaker. Mix the slurry thoroughly.

- Add $300 \mathrm{~mL}$ of distilled water and sulfuric acid to bring the $\mathrm{pH}$ within a 2.5 to 3.8 range.

- Fill the burette with methylene blue solution and add $5 \mathrm{~mL}$ of the methylene blue solution to the slurry, and stirred for vigorously.

- While the solids are still suspended, a glass rod is dipped into the solution.

- Place the tip of the glass rod on a filter paper where it will deposit a drop of mixture and dye.

- If a bluish turquoise ring is observed around the drop, the test has reached its end point. If the bluish turquoise ring does not appear around the drop, repeat steps 3, 4 and 5 .

Figure 4 shows a standard Methylene Blue test kit and sample test showing the bluish turquoise ring. Cation exchange capacity (CEC) can be calculated as follows:

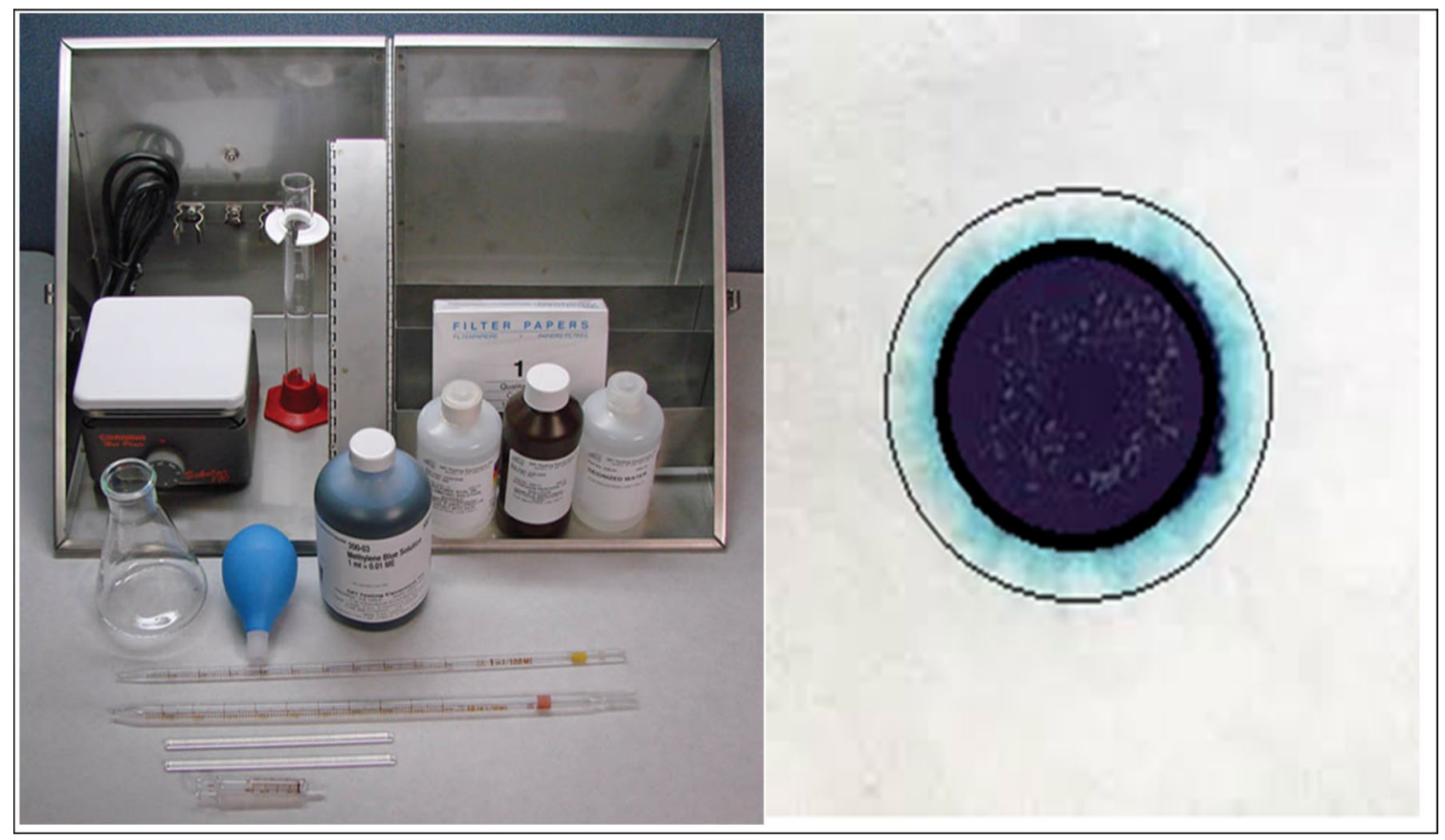

Fig. 4 A standard Methylene Blue test kit and sample test 
$\operatorname{CEC}(\%)=100\left(\frac{E * V}{W}\right)$

where

$C E C$ : Cation exchange capacity (meq/ $100 \mathrm{~g}$ ).

$E$ : Milliequivalents of methylene blue per milliliter.

$V$ : Milliliters of methylene blue solution at end point (titration).

$W$ : Weight of grounded shale (grams).

\section{Porosity and permeability determination}

To measure shale's porosity, standard API drying by heat methodology was applied as described in the following steps:

- Several cubical shale samples $(1$ ' $\times 1$ ", $\times 1$ ', $)$ were cut using a well lubricated electrical saw. Mineral oil was used for lubrication and cooling purposes.

- Weigh shale sample $\left(W_{1}\right)$.

- Dry the sample in a $200{ }^{\circ} \mathrm{F}$ oven for $24 \mathrm{~h}$. Actually, $24 \mathrm{~h}$ is sufficient to move all the free water inside the shale pores (Zhang et al. 2006).

- Weigh the shale sample after drying $\left(W_{2}\right)$.

- The volume of free water lost during the shale drying process $\left(V_{w}\right)$ is calculated as:

$V_{w}=\frac{W_{1}-W_{2}}{\rho_{w}}$

In the above notation, the water density equals to $1 \mathrm{~g} /$ $\mathrm{cm}^{3}$.

- The shale's pore volume $\left(V_{p}\right)$ equals the volume of free water lost during the shale drying process $\left(V_{w}\right)$ assuming that the shale samples are fully saturated with water.

- The shale sample's porosity $\left(\Phi_{i}\right)$ is calculated as:

$\Phi_{i}=\frac{V_{p}}{V_{t}}$

Here $V_{t}$ is the total shale sample volume which equals to $1 \mathrm{in}^{3}\left(16.39 \mathrm{~cm}^{3}\right)$ and $V_{p}$ is the estimated pore volume. Repeat the procedure for several samples to obtain their porosities.

- The average shale effective porosity is calculated as follows:

$\Phi_{a v g}=\frac{\sum \Phi_{i}}{n}$

This value will be used as the average native (initial) effective porosity for all shale samples taken from the same shale core. The above procedure was used to obtain the effective porosity of shales A and B.
Standard pressure transmission methodology, similar to that used by Oleas et al. (2010), was employed to obtain permeability of shales (A) and (B).

\section{Results and discussion}

\section{Impact of $\mathrm{K}^{+}$on shale swelling}

Shale $(A \& B)$ cores were taken out of the storage can and quickly washed using "Skelly-B" to get rid of all surface oil attached to the shale cores. Several samples of size $(0.75$ $" \times 0.75 " \times 1.0 ")$ were carefully cut from these cores to perform linear swelling tests. Each sample was placed in a small plastic bag and positioned between movable anvil and stationary anvil of a standard linear swelling device as shown in Fig. 5. A $50 \mathrm{ml}$ volume of $\mathrm{KCl}$ solution is poured in the plastic bag containing the shale sample and then air is squeezed out and the bag is sealed. The swelling and shrinkage percent was obtained by dividing the increase or decrease in length, shown as displacement readings, by the original sample length. A standard stop watch was used to record the time of shale swelling as shale sample interacts with the $\mathrm{KCl}$ solutions. Each test lasts for $24 \mathrm{~h}$. A plot of linear swelling versus time is generated on a semi-log plot. The objective of this work is to investigate the impact of only $\mathrm{K}^{+}$concentration on shale's physicochemical and mechanical properties as many have reported on the impact of other ions $\left(\mathrm{Na}^{+}, \mathrm{Ca}^{+2}\right.$ and $\mathrm{Mg}^{+2}$ ) on shale (Ghassemi et al. 2001; Hale and Mody 1992; Zhang et al., 2001; Yu et al. 2003; AL-Bazali 2013; Horsrud et al. 1998). Figure 6 shows $\mathrm{KCl}$ water activities and corresponding concentrations (\% wt). Figures 7 and 8 show swelling tests for shales $\mathrm{A}$ and $\mathrm{B}$, respectively, as they interacted with $\mathrm{KCl}$ solutions of 5, 15, $25 \%$ by weight. The water activities of $\mathrm{KCl}$ solutions corresponding to 5,15 and $25 \%$ concentrations are $0.973,0.922$ and 0.851 , respectively. Shale A and shale B water activities are 0.92 and 0.96 , respectively, as shown in Table 3.

It can be seen from Fig. 7 that shale (A) experienced swelling when interacting with 5 and $15 \% \mathrm{KCl}$ solutions while it experienced shrinkage when the $\mathrm{KCl}$ solution concentration was $25 \%$. This is expected since the water activity of shale $\mathrm{A}$ is 0.92 . Water flowed into shale when the water activity of $\mathrm{KCl}$ solution was higher than that of shale, and water flowed out of shale when the shale's water activity is higher than that of the solution. The amount of swelling seems to be proportional to the difference in water activities between shale and $\mathrm{KCl}$ solutions. Precisely, the higher the water activity imbalance, the higher the produced swelling or shrinkage. Figure 8 shows shale (B) swelling profile and it can be seen that shale B shrank when it interacted with lower water activity KCL solutions (15 and $25 \%$ by weight) and swelled when it contacted $5 \% \mathrm{KCl}$ solution. For both 
Fig. 5 Shale swelling test experimental setup
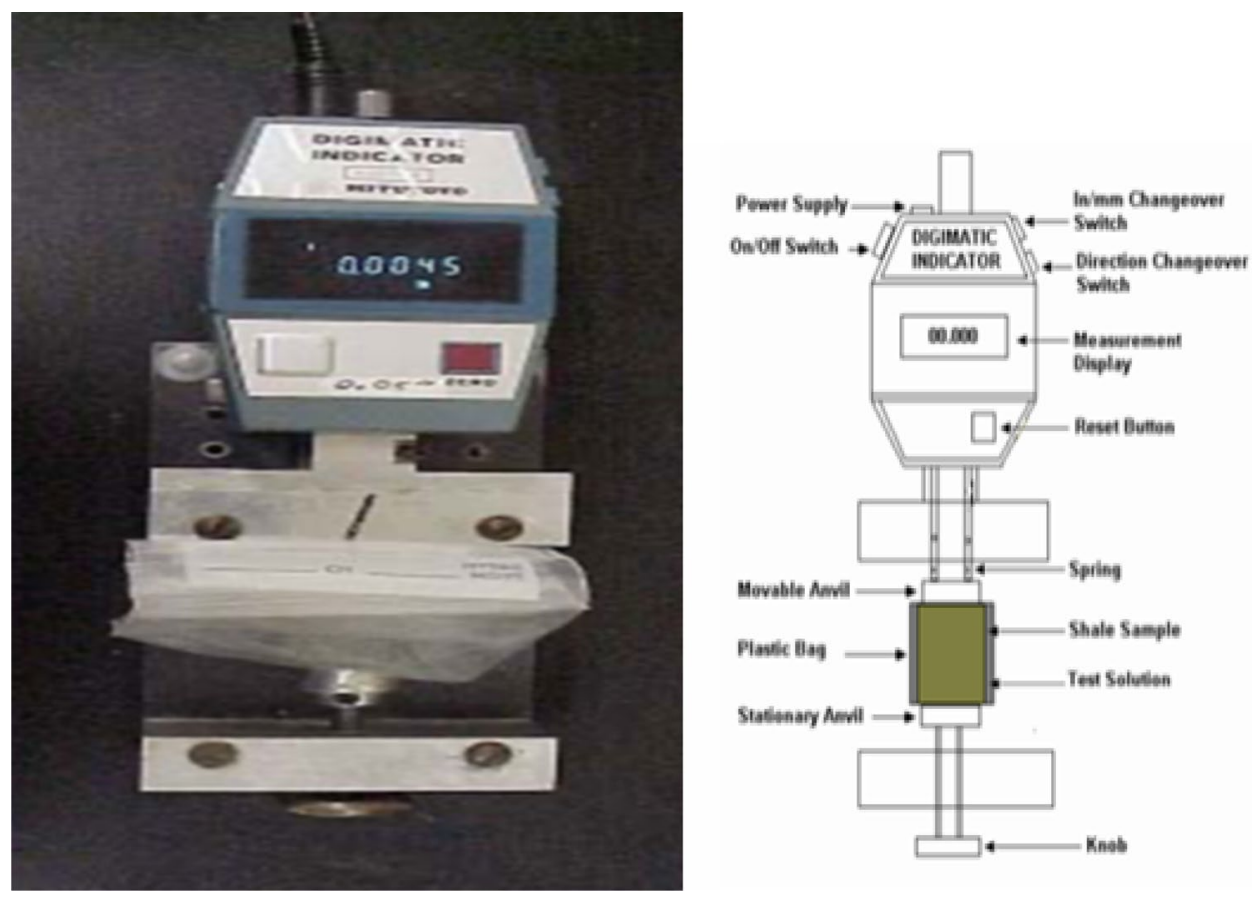

Fig. $6 \mathrm{KCl}$ solutions water activities and corresponding concentrations $(\% \mathrm{wt})$

\section{Water activities and corresponding concenteration for $\mathrm{KCl}$ solutions}

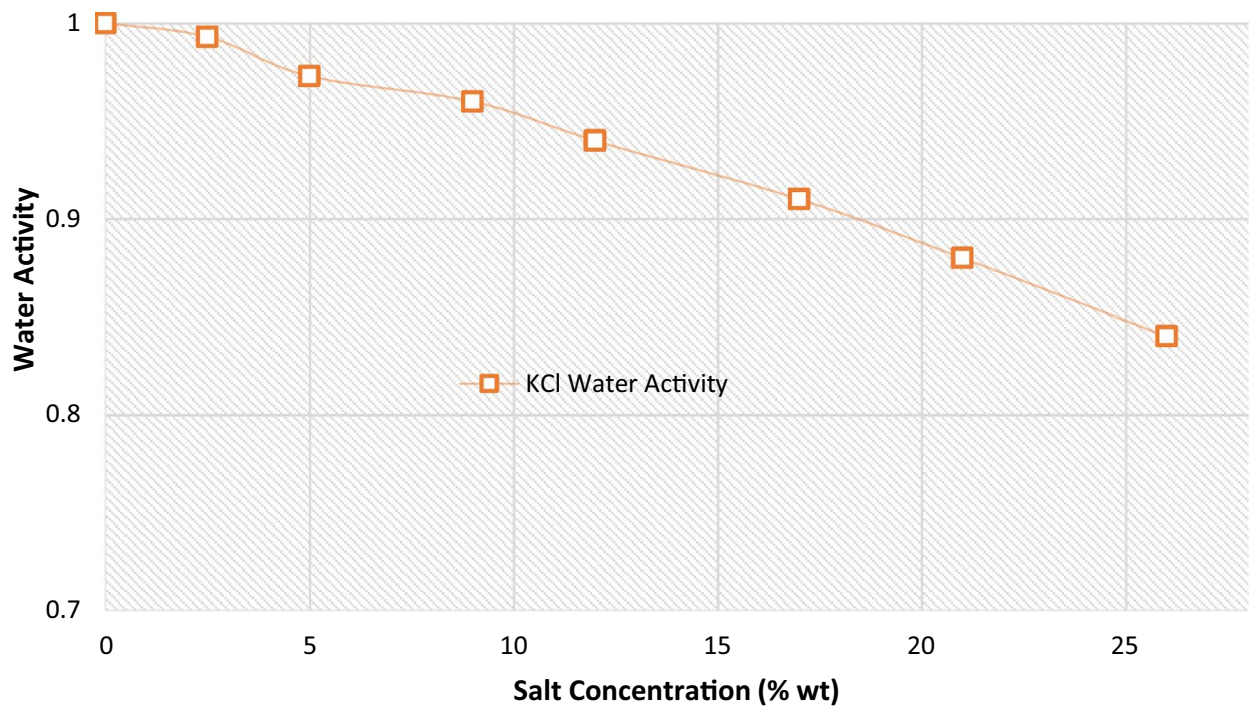

shales, increasing $\mathrm{KCl}$ concentration in the solution leads to a reduction in the amount of swelling which confirms the notion that the concentration of $\mathrm{KCl}$ solution plays a major role in inhibiting shale expansion. Jinag et al. (2014) results of linear swelling tests showed that potassium methylsiliconate exhibits a high performance as an effective shale inhibitor in drilling fluids where potassium ions promote the formation of a less hydratable structure of montmorillonite through cation-exchange interaction. Jonas and Thomas (1960) argued that there was a threshold $\mathrm{KCl}$ concentration at which potassium ions were absorbed in sufficient quantities to prevent expansion of the clay in water and at concentrations less than the threshold the material is characterized by a random interlayer mixture of expanding and nonexpanding layers. The mechanism for $\mathrm{KCl}$ inhibitory property is still not fully understood but it is argued that the size of potassium ion, unlike sodium and calcium ions, fits perfectly into the clay lattice structure and thus greatly reduces hydration and swelling of clays (Seppälä et al. 2016; O'Brien and Chenevert 1973; Mondshine 1973; Steiger 1982; Horsrud 
Fig. 7 Shale A swelling response when exposed to $\mathrm{KCl}$ solutions at 5,15 and $25 \%$ concentrations

\section{Shale (A) swelling response when exposed to $\mathrm{KCl}$ solutions of different concentrations}

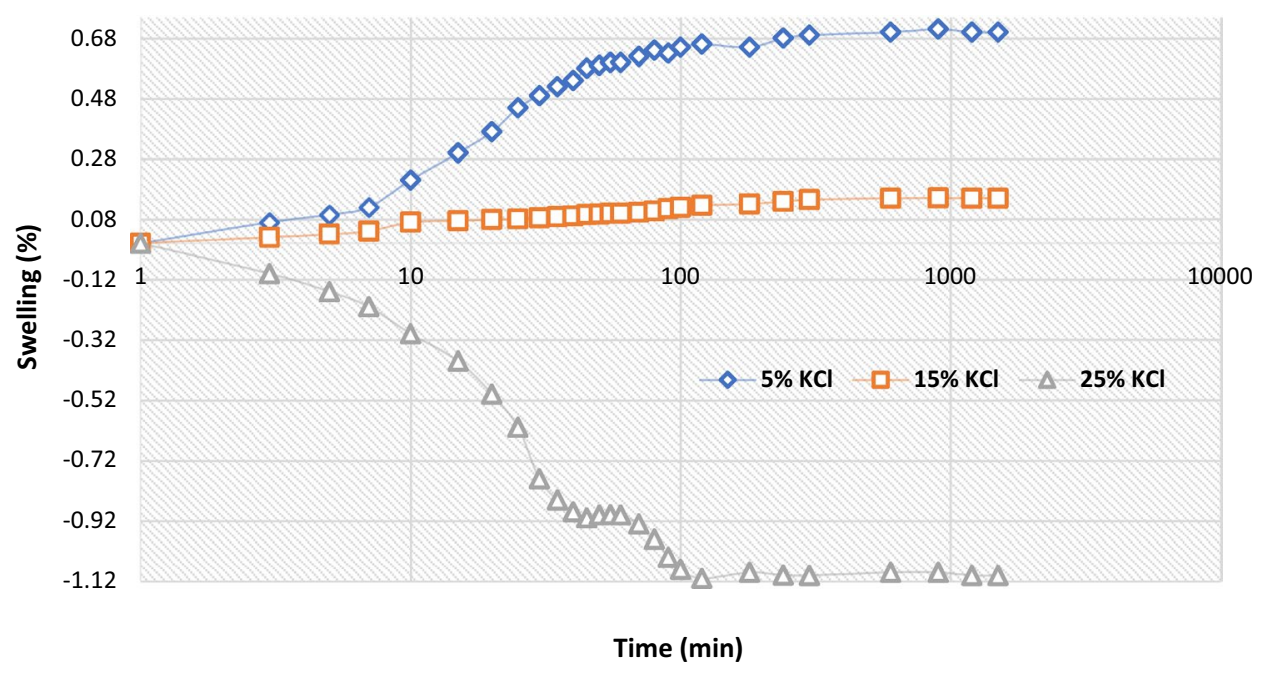

Fig. 8 Shale B swelling response when exposed to $\mathrm{KCl}$ solutions at 5,15 and $25 \%$ concentrations

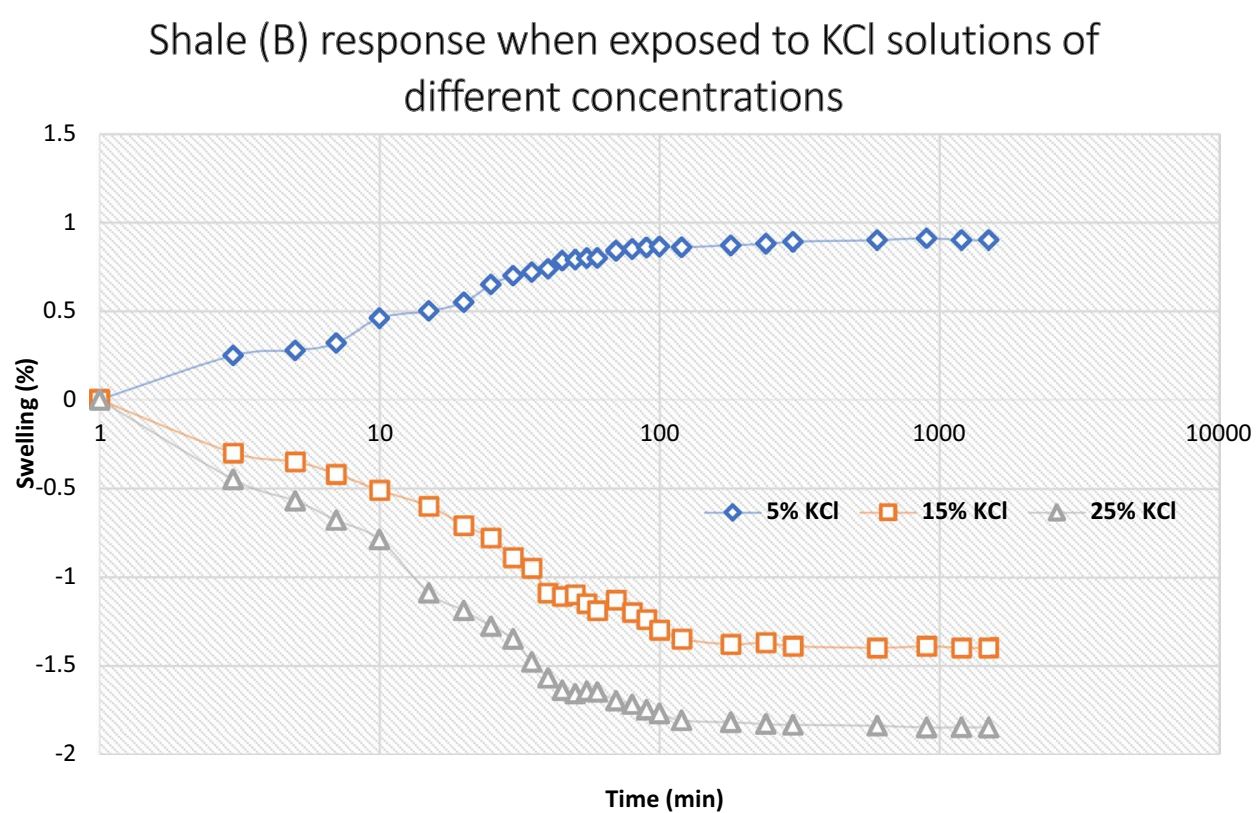

et al. 1998). It is possible that the presence of potassium ions at sufficient concentrations reduces the thickness of the diffuse double layer which reduces the expansion tendency of clays. If sufficient shrinkage occurs to the diffuse doublelayer thickness of interacting clay particles, van der Waals forces become more dominant over electrostatic repulsive forces which causes clay particles to attract each other and thereby provide more stability and prevent clay swelling (Anandarajah and Chen 1997). In fact, it is argued that the double-layer thickness decreases with increasing valence and concentration (Schmitz 2006; Pashley and Quirk 1984; Bohinc et al. 2001; Ruzanov et al. 2018). The thickness of the diffuse double layer is approximated by the Debye length. In an electrolyte or a colloidal suspension, the Debye length for a monovalent electrolyte is frequently represented with symbol $\kappa^{-1}$ as follows:

$\kappa^{-1}=\sqrt{\frac{\varepsilon_{r} \varepsilon_{0} k_{B} T}{2 N_{A} e^{2} I}}$

where

$\varepsilon_{r}$ : Dielectric constant.

$\varepsilon_{0}$ : Permittivity of free space.

$k_{\mathrm{B}}$ : Boltzmann constant. 
$T$ : The absolute temperature in Kelvins.

$N_{\mathrm{A}}$ : Avogadro number.

$e$ : elementary charge.

$I$ : Ionic strength of the electrolyte in molar units ( $\mathrm{M}$ or $\mathrm{mol} / \mathrm{L})$.

Figure 9 shows a simulated Debye length $(n \mathrm{~m})$ as a function of ionic strength (mol/l) for monovalent ions. It is clearly seen from Fig. 9 that the Debye length decreases as the ionic concentration increases. This explains why concentrated potassium chloride solutions tend to suppress shale swelling as higher concentration of potassium ions collapses the diffuse double layer of clay particles making way for van der Waals forces to overtake electrostatic repulsive forces between clay particles which eventually causes shale shrinkage as shown by Figs. 7 and 8

While shale swelling data show us the impact of $\mathrm{K}^{+}$on expansivity of shale, such data does not give us a complete understanding of the physicochemical and mechanical alterations that shale experiences when exposed $\mathrm{K}^{+}$. Relying on swelling data alone to mitigate wellbore instability in shales is meaningless and pointless. Such data must be accompanied by other mechanical and physicochemical data for complete and accurate wellbore instability analysis. I think mechanical data, compressive strength, and ions and water uptake analysis when shale interacts with potassium ions need to be investigated and incorporated with swelling data for better analysis and mitigation of wellbore instability in shales. Furthermore, the concentration of potassium ions in solution may be key at understanding how potassium ions prevent shale expansion and could shed light on the alteration of shale's mechanical properties.

\section{Impact of $\mathrm{K}^{+}$on shale mechanical properties}

Shale samples were placed inside a triaxial cell to measure its unconfined compressive strengths. Prior to applying an axial load to the rock sample, a confining pressure of $35 \mathrm{MPa}$ was applied over a period of $15 \mathrm{~min}$, then was held constant for one hour to make sure that the pore pressure within the sample has completely dissipated before axial load is applied. At the start of test, the confining pressure was set to zero so that unconfined compressive strength can be measured. A $3.0 \times 10^{-5} \mathrm{~s}^{-1}$ axial strain rate was applied until failure occurred. Additional experimental details can be found elsewhere (AL-Bazali 2013). A schematic of the triaxial rock testing system used to measure uniaxial compressive strength of shale is shown in Fig. 10.

Figure 11 shows native "unaltered" and measured "altered" compressive strength of shales A and B when exposed to $\mathrm{KCl}$ solutions of $2.5,5,10,15$ and $25 \%$ by weight concentrations. Some interesting observations can be made from Fig. 11. The reduction in uniaxial compressive strength of both shales was negligible at $\mathrm{KCl}$ concentrations less than $5 \%$ by weight. In fact, at $5 \% \mathrm{KCl}$ concentration, the reduction in compressive strength of shale A was $1.5 \%$ while shale B showed a $2.5 \%$ reduction in compressive strength. Could the reduction in compressive strength be attributed to development of swelling and hydrational stresses in shales since the water activities of $\mathrm{KCl}$ solutions, at 5\% $\left(a_{w}=0.973\right)$ and $2.5 \%\left(a_{w}=0.993\right)$ concentrations, were higher than that of shale A $\left(a_{w}=0.92\right)$ and shale B $\left(a_{w}=0.96\right)$ ? The magnitude of compressive strength loss for both shales does not reflect the magnitude of chemical potential imbalances between these shales and the $2.5 \%$ and $5 \% \mathrm{KCl}$ solutions. According to Eq. (1), the developed osmotic swelling pressures when
Fig. 9 Simulated Debye length $(n \mathrm{~m})$ as a function of ionic strength $(\mathrm{mol} / \mathrm{l})$

\section{Debye length $(\mathrm{nm})$ dependence on ionic strength (mol/L)}

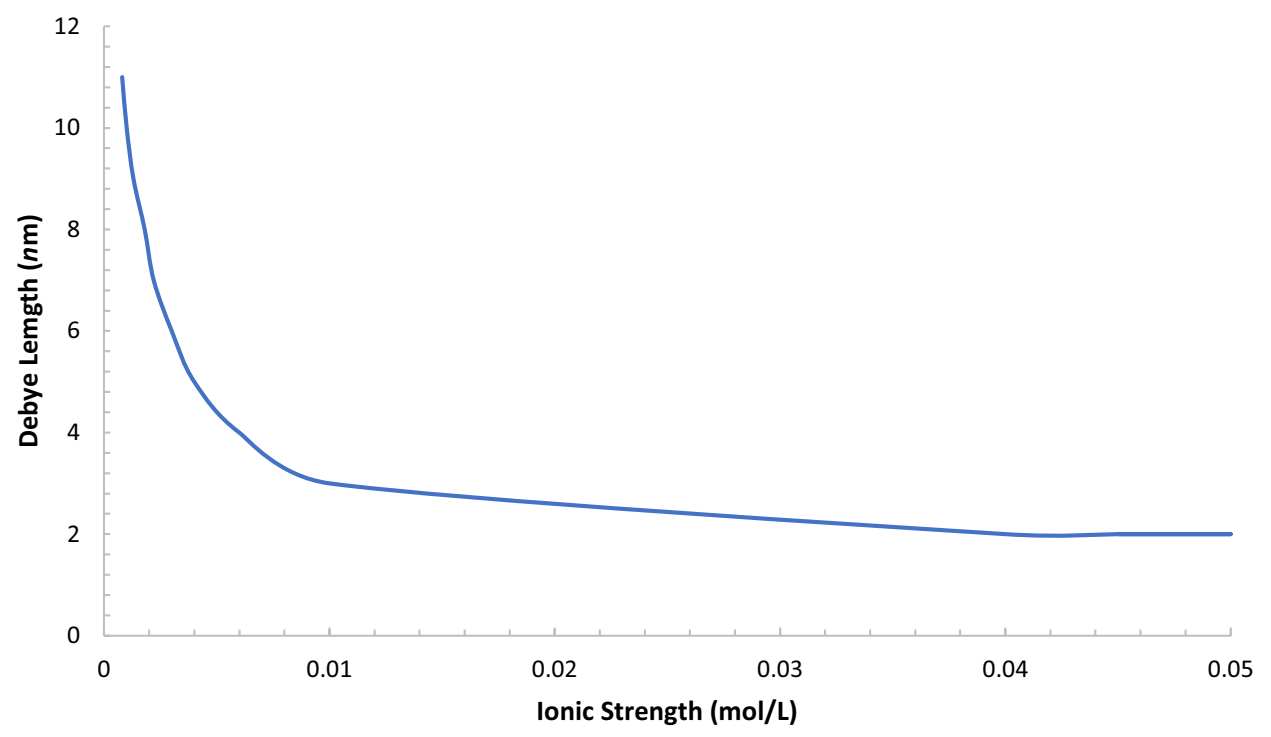


Fig. 10 Schematic of the triaxial rock testing system used to measure uniaxial compressive strength of shale
Fig. 11 Measured uniaxial compressive strength of shales $(\mathrm{A} \& \mathrm{~B})$ at different concentrations of 1 solutions

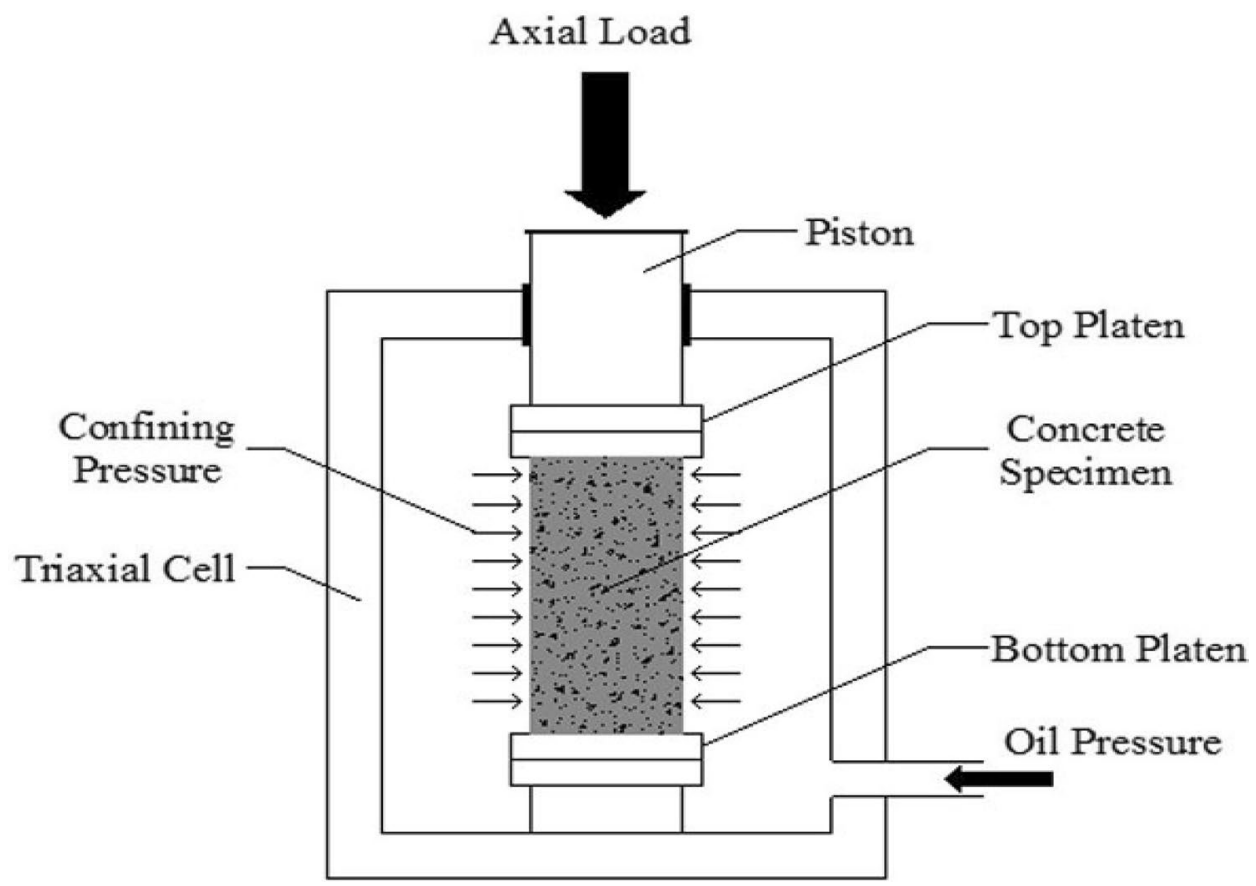

\section{Measured unconfined compressive strengths of shales (A\&B) at different concentrations of $\mathrm{KCl}$ solutions}

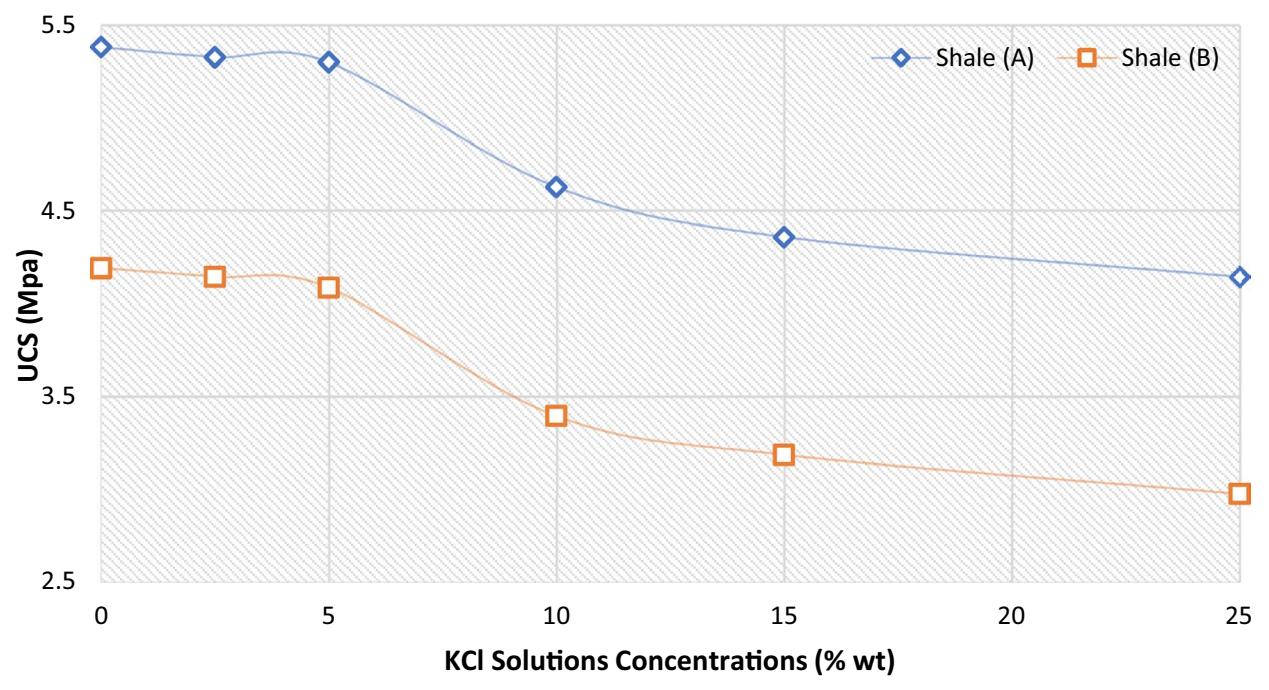

shale A interacted with 5 and $2.5 \% \mathrm{KCl}$ solutions equal 7.58 and 10.336 MPa, respectively. Similarly, osmotic swelling pressures when shale B interacted with 5 and $2.5 \% \mathrm{KCl}$ solutions equal 1.82 and $4.575 \mathrm{MPa}$, respectively.

Despite the calculated high swelling pressures which should eventually lead to hydrational stresses inside the rock, the compressive strength of both shales was not greatly affected. AL-Bazali et al. (2006) showed that shale acts as a leaky semi-permeable membrane where it does not completely restrict ionic transport and that the efficiency of its membrane is quite low and does not exceed $10 \%$ on average.
Such low membrane efficiency will lower the theoretical swelling pressure calculated by Eq. (1) by average of $90 \%$ and that indeed dampened its hydrational stresses acting on shale. The flow of ions and their associated water into the shale, owing to imposed ionic concentrations imbalance, could partially dissolve the cementing bonds between the grains, reduce the friction between the grains, introduce micro-fractures and fissures and eventually cause strength reduction (AL-Bazali 2011). Therefore, it is quite possible that the reduction in shale's compressive strength was mainly caused by the invasion of ions and their associated 
water, also known as diffusion osmosis, into shale and not so much by shale swelling and their associated hydrational stresses. It is fair to state that hydrational stresses caused by shale swelling may have partially contributed to shale's strength reduction but their effect is far less than that of diffusion osmosis despite the imposed low ionic concentration difference. If hydrational stresses induced by osmotic swelling had more impact on shale's strength, we would expect the reduction in shale's strength to be much higher especially at those predicted osmotic pressures resulting from chemical potential imbalances.

The compressive strength for both shales considerably decreased when the concentration of $\mathrm{KCl}$ solutions were higher than $5 \%$ by weight. In fact, shales A and B compressive strengths were reduced by 23 and $29 \%$, respectively, when $\mathrm{KCl}$ solution of $25 \%$ by weight concentration was used. It is interesting to notice that both shales shrank when exposed to $25 \%$ by weight $\mathrm{KCl}$ solutions as seen in Figs. 7 and 8 . The calculated theoretical osmotic pressure equals - 10.71 MPa for shale A and - 16.47 MPa for shale B. Applying a $10 \%$ average membrane efficiency of shale, the expected osmotic pressures will be $-1.071 \mathrm{MPa}$ for shale A and - 1.647 MPa for shale $\mathrm{B}$. These negative osmotic pressures should be high enough to provide stability to shale; however, the shale's compressive strength was reduced significantly. I believe that the loss of cohesive strength in both shales could be mostly attributed to diffusion osmosis where more ions and their associated water invaded the shale owing to the larger imposed ionic concentration imbalance between shale and $\mathrm{KCl}$ solutions. Similar analysis can be drawn on shales interactions with $\mathrm{KCl}$ solutions at $10 \%$ and $15 \%$ by weight concentrations.

It is obvious from Fig. 11 that there exists a threshold of $\mathrm{KCl}$ concentration above which shale's compressive strength deteriorates significantly. This concentration threshold hovers around 5\% as shown in Fig. 11. Both shales show conservative stability when $\mathrm{KCl}$ concentration is less than 5\%; however, mechanical instability that is manifested in compressive strength reduction becomes greater when $\mathrm{KCl}$ concentration is greater than $5 \%$.

To further investigate this issue, the amounts of ions and water transport into shale as it interacts with $\mathrm{KCl}$ solutions need to be separately quantified as discussed in the next section.

\section{Impact of $\mathrm{K}^{+}$on water and ions uptake into shale}

The amount of water and ions uptake into shale when exposed to $\mathrm{KCl}$ solutions of different concentrations is determined by the application of a gravimetric technique where weight changes of well-preserved shale samples are taken for different samples conditions. The following equations are employed in connection with gravimetric measurements to calculate the weight percent of water and ions gained or lost as a results of shale interaction with $\mathrm{KCl}$ solutions.

$W w \%=\left(\frac{W_{3}-W_{4}-W_{1}+W_{2}}{W_{1}}\right) * 100 \%$

$W i \%=\left(\frac{W_{4}-W_{2}}{W_{1}}\right) * 100 \%$

$W_{l}$ : Weight of preserved sample in air.

$W_{2}$ : Weight of preserved sample after drying.

$W_{3}$ : Altered weight of sample after immersion in solutions.

$W_{4}$ : Dry weight of altered sample.

$W_{w} \%$ : Water transferred into (gain) or out of (loss) shale.

$W_{i} \%$ : Weight of ions $\left(\mathrm{K}^{+}\right.$and $\left.\mathrm{Cl}^{-}\right)$transferred into (gain) or out of (loss) shale.

It is important to mention that $W_{w} \%$ obtained by Eq. (9) represents net water $\%$ uptake into or out of shale. The net water is a combination of water transported osmotically due to the presence of chemical potential (water activity) difference and water transported along with diffusing ions, associated water, owing to ionic concentrations imbalances between shale and $\mathrm{KCl}$ solutions. Other gravimetric techniques were used to distinguish the amount of ions uptake from the amount of water uptake when shale interacts with salt solutions (Zhang et al. 2004; AL-Bazali 2013).

Figures 12 and 13 show the amount of water and ions transported into or out of shale as a result of exposure to $\mathrm{KCl}$ solutions at 5, 15 and $25 \%$ concentrations by weight. It is clearly shown that both shales gained ions and water when exposed to $\mathrm{KCl}$ solutions at 5,15 and $25 \%$ concentrations. The uptake of ions into both shales resulted from the imposed ionic concentration gradients where ions diffused from higher concentration regions to lower concentration regions as per Fick's law in Eq. (2). Combining results from Figs. 12 and 13 with those from Fig. 11, we can relate the compressive strength reduction with the amount of ions uptake into shale. In fact, the threshold concentration (5\%) above which reduction in shale's compressive strength becomes significant is clearly explained in Figs. 12 and 13 where the amount ions uptake into shale increases dramatically for $\mathrm{KCl}$ concentrations higher than $5 \%$. Shale (A) experienced a $1.5,19$ and $23 \%$ reduction in compressive strength when exposed to 5,15 and $25 \% \mathrm{KCl}$ solutions correspondingly while shale (B) exhibited a 2.5, 24 and $29 \%$ reduction in compressive strength when exposed to 5,15 and $25 \% \mathrm{KCl}$ solutions correspondingly. The invasion of ions could dissolve cementing and reduce friction between grains, induce fissures and microfractures and affect the shale's fabric and mechanical structure. The adverse impact of ionic invasion on shale's mechanical properties especially compressive strength has been widely studied and reported (AL-Bazali

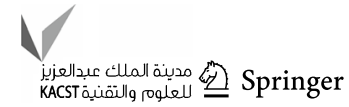


Fig. 12 The amount of water and ions transported into or out of shale $(\mathrm{A})$ as a result of exposure to $\mathrm{KCl}$ solutions at 5 , 15 and $25 \%$ concentrations by weight

Fig. 13 The amount of water and ions transported into or out of shale (B) as a result of exposure $\mathrm{KCl}$ solutions at 5,15 and $25 \%$ concentrations by weight

\section{Water \& ions uptake into shale $(\mathrm{A})$ when exposed to $\mathrm{KCl}$ solutions}
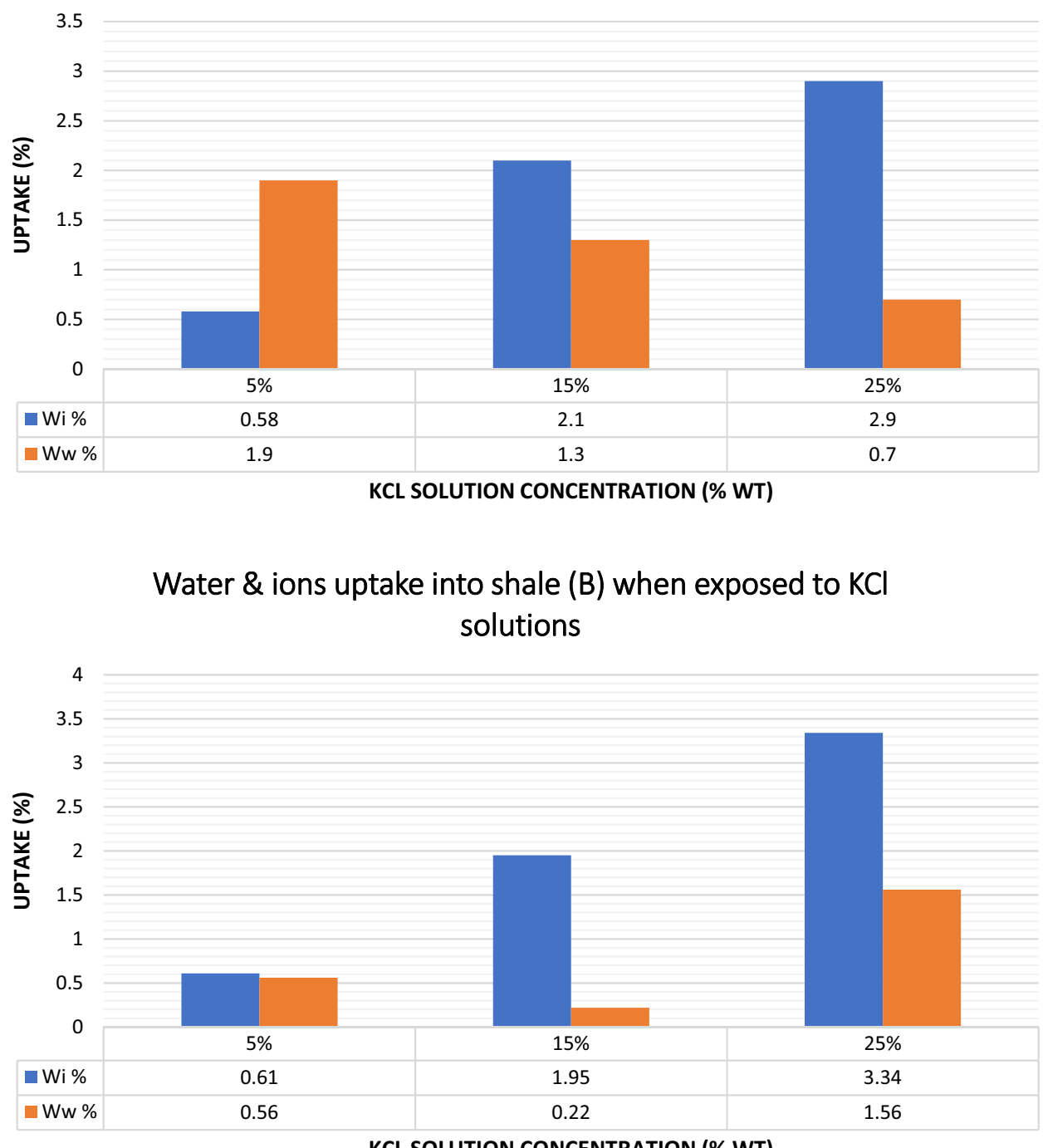

KCL SOLUTION CONCENTRATION (\% WT) et al. 2008; Bol et al. 1992; Carminati et al. 1999; Zhang et al. 2004; Fam and Dusseault 1998; Horsud et al. 1998; Low and Anderson 1958).

Figures 12 and 13 show that water transported into both shales when exposed to 5,15 and $25 \% \mathrm{KCl}$ solutions. This is counter intuitive since the water activities of 15 and $25 \%$ $\mathrm{KCl}$ solutions are lower than those of shales A and $\mathrm{B}$. This fact is shown osmotically in Figs. 7 and 8 where significant shale shrinkage took place when exposed to 15 and $25 \% \mathrm{KCl}$ solutions owing to the imposed chemical potential (water activity) gradients. It turned out that water is transported into shale by two mechanisms: osmosis and diffusion osmosis. Osmotic water is water movement due to chemical potential (water activity) gradient while associated water is water movement along diffusing ions in the presence of an ionic concentration gradient. What we observe in Figs. 12 and 13 is the net amount of transported water in shales where both osmotic and associated water are included.

\section{Role of adsorbed water: swelling versus strength reduction}

To separate the amount of osmotic water from the amount of associated water, an extended gravimetric technique developed by AL-Bazali (2013) is employed. Figures 14 and 15 show osmotic water and associated water uptake into shales $\mathrm{A}$ and $\mathrm{B}$, respectively, as a result of exposure to $\mathrm{KCl}$ solutions at 5, 15 and $25 \%$ concentrations by weight. A close look at Figs. 14 and 15 reveals that water was osmotically drawn out of both shales when exposed to 15 and $25 \% \mathrm{KCl}$ solutions where it was transported into both shales when exposed to $5 \% \mathrm{KCl}$ solution. This is consistent with shale 


\section{Osmotic water vs. Associated water for shale (A) water uptake \%}

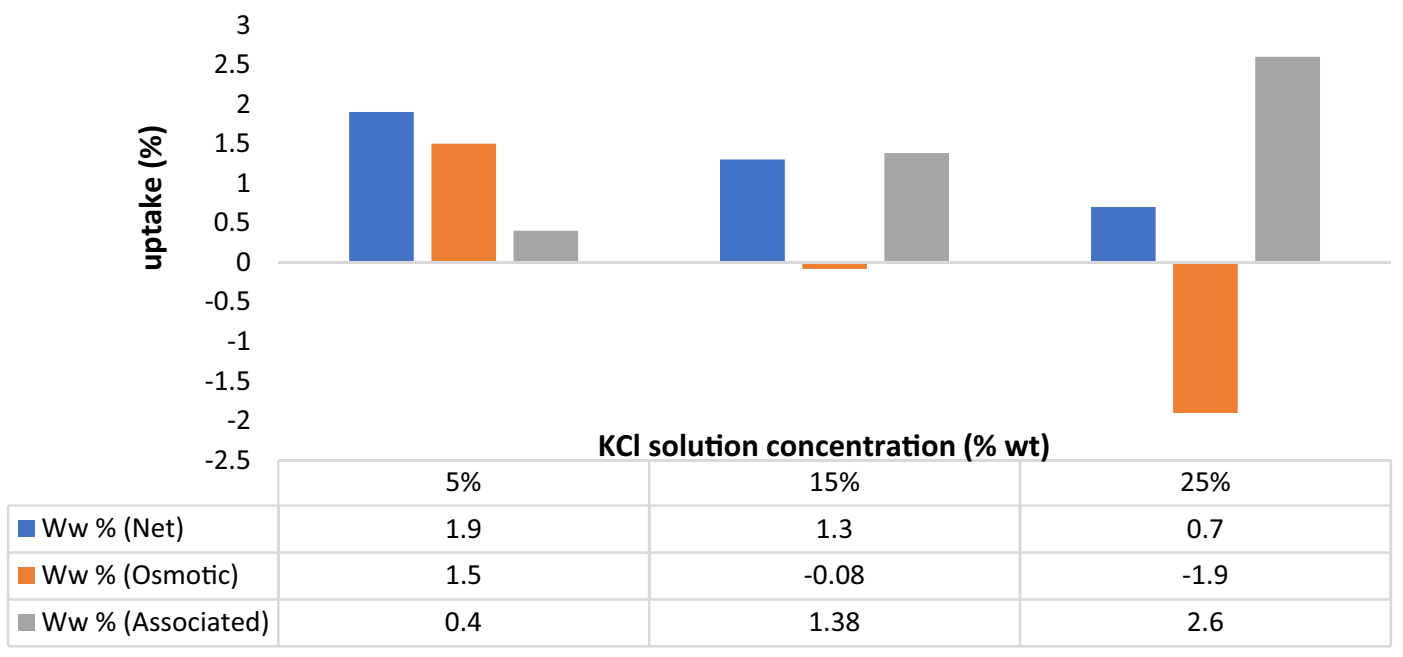

Fig. 14 Osmotic water and associated water uptake into shale (A) as a result of exposure to $\mathrm{KCl}$ solutions at 5,15 and $25 \%$ concentrations by weight

Fig. 15 Osmotic water and associated water uptake into shale (B) as a result of exposure to $\mathrm{KCl}$ solutions at 5,15 and $25 \%$ concentrations by weight

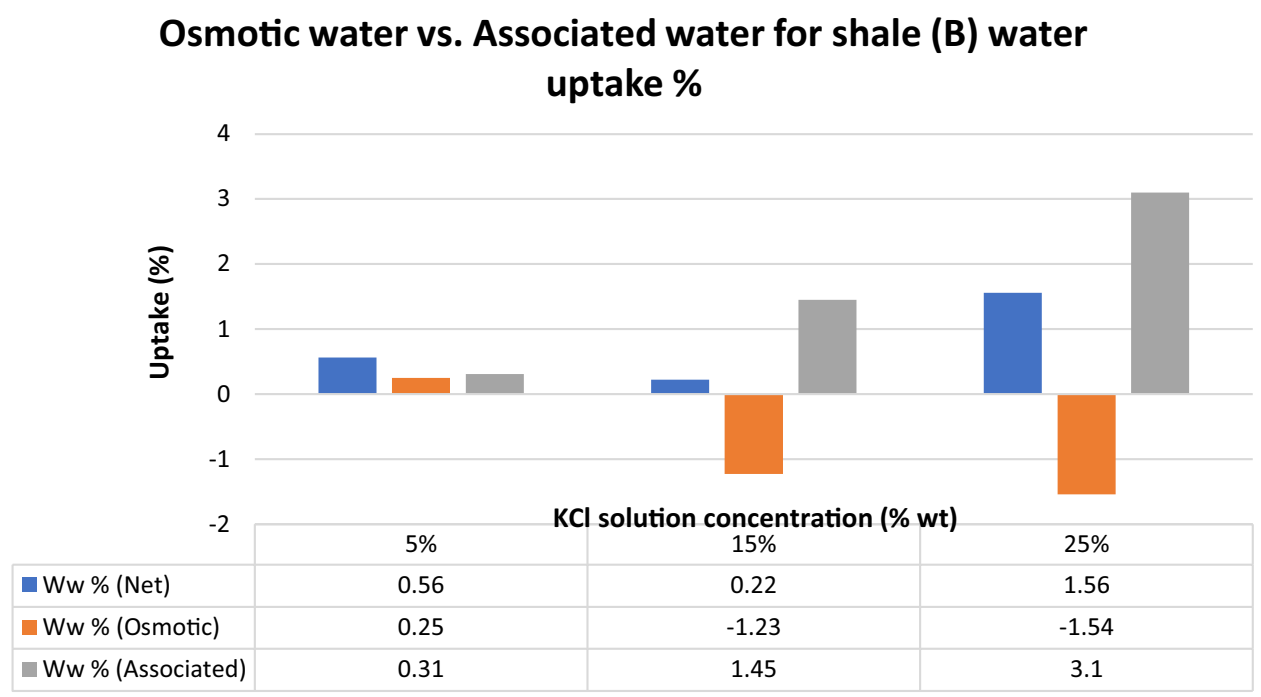

swelling and shrinkage behavior as exhibited in Figs. 7 and 8. Furthermore, it can be seen from Figs. 14 and 15 that associated water always flowed along with its diffusive ions into shale. The amount of associate water is always higher than the amount of osmotic water except when $5 \% \mathrm{KCl}$ solution is used.

It is worth noting that both shales gained water at all $\mathrm{KCl}$ concentrations (5, 15 and $25 \%$ ); however, shale A shrank when exposed to $25 \% \mathrm{KCl}$ solution and shale $\mathrm{B}$ also shrank when exposed to 15 and $25 \% \mathrm{KCl}$ solutions as shown in Figs. 7 and 8. This brings up a very interesting question; why would shale shrink if it gained water?
The answer to this important question could be related to the different roles osmotic and associated waters have on shales. I think that osmotic water is responsible for shale swelling since it is unattached to ions which makes it free to move around inside shale while the role of associated water is restricted to accompanying ions which makes them unfree to move around as much. So, most swelling and shrinkage experienced by shales A and B can attributed to osmotic water uptake while compressive strength reduction could be mainly attributed to ionic diffusion and associated water. 


\section{Conclusions and recommendations}

This study integrated the impact of potassium ion on shale's physicochemical and mechanical properties by performing sets of gravimetric measurements and uniaxial compression testing on two different shale cores. The following key points can be deduced from this study.

- Concentrated potassium chloride solutions tend to suppress shale swelling as higher concentration of potassium ions collapses the diffuse double layer of clay particles causing shale shrinkage.

- The Debye length $\left(\kappa^{-1}\right)$ decreases as the ionic concentration increases.

- van der Waals forces dominate electrostatic repulsive forces between clay particles at high salt concentrations and thereby promoting clay stability.

- Swelling data alone is not adequate to mitigate wellbore instability. Such data must be incorporated with mechanical and physicochemical data for complete and accurate wellbore instability analysis.

- The swelling and shrinkage magnitude observed by shale (B) is higher than that of shale (A) and this could be related to the fact that the amount of total clay, especially reactive clay (smectite), is higher for shale (B) than shale (A).

- There exists a threshold of $\mathrm{KCl}$ concentration above which shale's compressive strength deteriorates significantly. This concentration threshold hovers around 5\%.

- The invasion of ions could dissolve cementing and reduce friction between grains, induce fissures and microfractures and affect the shale's fabric and mechanical structure.

- Osmotic water is responsible for shale swelling since it is unattached to ions which makes it free to move around inside shale.

- The role of associated water is restricted to accompanying ions which makes them unfree to move around.

Funding The author declares that there was no funding, grants, or other support was received for conducting this study. Moreover, the author has no relevant financial or non-financial interests to disclose.

Open Access This article is licensed under a Creative Commons Attribution 4.0 International License, which permits use, sharing, adaptation, distribution and reproduction in any medium or format, as long as you give appropriate credit to the original author(s) and the source, provide a link to the Creative Commons licence, and indicate if changes were made. The images or other third party material in this article are included in the article's Creative Commons licence, unless indicated otherwise in a credit line to the material. If material is not included in the article's Creative Commons licence and your intended use is not permitted by statutory regulation or exceeds the permitted use, you will need to obtain permission directly from the copyright holder. To view a copy of this licence, visit http://creativecommons.org/licenses/by/4.0/.

\section{References}

Al-Bazali TM (2011) 'The consequences of using concentrated salt solutions for mitigating wellbore instability in shales.' J Petrol Sci Eng 80(1):94-101

Al-Bazali T (2013) The impact of water content and ionic diffusion on the uniaxial compressive strength of shale. Egypt J Pet 22(2):249-260

Albazali TM, Zhang J, Chenevert ME, Sharma MM (2008) An experimental investigation on the impact of diffusion osmosis, chemical osmosis, and capillary suction on shale alteration. J Od Porous Med 11(8):719-731

Anandarajah A, Chen J (1997) Van der Waals attractive force between clay particles in water and contaminants. Soils Found 37(2):27-37

American Society for Testing and Materials (1988) ASTM C 837-81. Standard Test Methods of Methylene Blue Index of Clay

Bohinc K, Kralj-Iglič V, Iglič A (2001) Thickness of electrical double layer. Eff Ion Size ELectrochimica Acta 46(19):3033-3040

Bol GM, Wong SW, Davidson CJ, Woodland DC (1992) Borehole stability in shale, SPE Paper 24975. Presented at the European petroleum conference in Cannes, Nov 16-18

Breeden D, Shipman J (2004) "Shale Analysis for Mud Engineers", AADE-04-DF-HO30 presented at the AADE 2004 Drilling Fluids Conference, at the Radisson Astrodome in Houston, Texas, April 6-7

Bybee K (2009) Wellbore-stability performance of water-based-mud additives. J Petrol Technol 61(09):78-79

Cao C, Pu X, Wang G, Huang T (2018) Comparison of shale inhibitors for hydration, dispersion, and swelling suppression. Chem Technol Fuels Oils 53(6):966-975

Carminati S, Del Gaudio L, Zausa F, Brignoli M (1999) How do anions in water-based muds affect shale stability? SPE 50712. SPE international symposium on oilfield chemistry, Houston, 16-19

Chenevert ME (1969) Shale Alteration by Water Adsorption, SPE 2401 presented at the SPE Fourth Conference on Drilling and Rock Mechanics held in Austin, Texas, Jan. 14-15

Chenevert, M. E., and Amanullah, M., (1997) "Shale Preservation and Testing Techniques for Borehole Stability Studies", SPE/IADC Paper 37672, Presented at the SPE/IADC Drilling Conference in Amsterdam, The Netherlands March 4-6

Denis JH, Keall MJ, Hall PL, Meeten GH (1991) Influence of potassium concentration on the swelling and compaction of mixed (Na, K) ion-exchanged montmorillonite. Clay Miner 26(2):255-268

Dzialowski, A., Hale, A., \& Mahajan, S. (1993) Lubricity and Wear of Shale: Effects of Drilling Fluids and Mechanical Parameters", SPE/IADC Paper 25730, Presented at the SPE/IADC Drilling Conference in Amsterdam.

Ewy, R.T. and Stankovich R. J. (2000) Pore pressure change due to shale-fluid interaction: measurements under simulated wellbore conditions, presented at the Proceedings Pacific Rocks 2000, Fourth North American Rock Mechanics Symposium, Seattle, July 31-Auguest 3, pp147-154, Balkema, Rotterdam.

Fam MA, Dusseault MB (1998) Borehole stability in shales: a physicochemical perspective' SPE-47301, presented in SPE/ISRM rock mechanics in petroleum engineering. Trondheim, Norway

Ghassemi, A., Diek, A., \& Santos, H. (2001) "Effects of Ion Diffusion and Thermal Osmosis on Shale Deterioration and borehole 
Instability" AADE 01-NC-HO-40, Presented at the AADE 2001 National Drilling Conference held in Houston, Texas.

Hale, A. H., and Mody, F. K. (1992) "Experimental Investigation of the Influence of Chemical Potential on Wellbore Stability", IADC/ SPE Paper 23885, Presented at the SPE/IADC Drilling Conference in New Orleans, Louisiana.

Horsrud, P., Bostrom, B., Sonstebo, E. F., \& Holt, R. M. (1998). Interaction between shale and water-based drilling fluids: laboratory exposure tests give new insight into mechanisms and field consequences of $\mathrm{KCl}$ contents. In SPE annual technical conference and exhibition. Society of Petroleum Engineers

Jianguo Zhang, M E Chenevert, Talal AL-Bazali, and M M Sharma (2004) "A New Gravimetric - Swelling Test for Evaluating Water and Ion Uptake of Shales" SPE 89831 Presented at the SPE Annual Technical Conference and Exhibition held in Houston, Texas, USA., 26-29.

Jiang G, Xuan Y, Li Y, Wang J (2014) Inhibitive effect of potassium methylsiliconate on hydration swelling of montmorillonite. Colloid J 76(4):408-415

Jonas, E. C., \& Thomas, G. L. (1960). Hydration properties of potassium deficient clay micas. In Clays and clay minerals (pp. 183192). Pergamon?

Lomba RF, Chenevert ME, Sharma MM (2000) The role of osmotic effects in fluid flow through shales. J Petrol Sci Eng 25(1-2):25-35

Low PF, Anderson DM (1958) Osmotic pressure equations for determining thermodynamic properties of soil water. Soil Sci $86: 251-253$

Lu C-F (1988) A new technique for the evaluation of shale stability in the presence of polymeric drilling fluid. SPE Prod Eng 3(03):366-374

Madsen FT, Müller-Vonmoos M (1989) The swelling behaviour of clays. Appl Clay Sci 4(2):143-156

Meng M, Ge H, Shen Y, Ren F, Ji W (2020) A novel method for monitoring the imbibition behavior of clay-rich shale. Energ Rep 6:1811-1818

Mondshine TC (1973) A new potassium based mud system. In Fall Meeting of the Society of Petroleum Engineers of AIME, Society of Petroleum Engineers

Naeimavi M, Khazali F, Abdideh M, Saadati Z (2021) Potassium sorbate as substitute for $\mathrm{KCl}$ to shale inhibition in water-base drilling fluids. Energ Sour Part A: Recover Util Environ Eff 43(14):1691-1705

O'Brien DE, Chenevert ME (1973) Stabilizing sensitive shales with inhibited, potassium-based drilling fluids. J Petrol Technol 25(09):1089-1100

Oleas AM, Osuji CE, Chenevert ME, Sharma MM (2010) Entrance pressure of oil-based mud into shale: effect of shale, water activity, and mud properties. SPE Drill Complet J 25(1):39-44

Pashley RM, Quirk JP (1984) The effect of cation valency on DLVO and hydration forces between macroscopic sheets of muscovite mica in relation to clay swelling. Colloids Surf 9(1):1-17

Ruzanov A, Lembinen M, Jakovits P, Srirama SN, Voroshylova IV, Cordeiro MND, Pereira CM, Rossmeisl J, Ivaništšev VB (2018)
On the thickness of the double layer in ionic liquids. Phys Chem Chem Phys 20(15):10275-10285

Santarelli, F.J. \& Carminati S (1995) Do Shales Swell? A Critical Review of Available Evidence, SPE-29421 presented at the SPE/ IADC Drilling Conference, Amsterdam, Netherlands.

Schmitz RM (2006) Can the diffuse double layer theory describe changes in hydraulic conductivity of compacted clays? Geotech Geol Eng 24(6): 1835-1844

Seppälä A, Puhakka E, Olin M (2016) Effect of layer charge on the crystalline swelling of $\mathrm{Na}^{+}, \mathrm{K}^{+}$and $\mathrm{Ca}^{2+}$ montmorillonites, DFT and molecular dynamics studies. Clay Miner 51(2):197-211

Shi X, Wang L, Guo J, Su Q, Zhuo X (2019) Effects of inhibitor $\mathrm{KCl}$ on shale expansibility and mechanical properties. Petrol 5(4):407-412

Simpson, J. P., \& Dearing, H. L. (2000). Diffusion Osmosis-An unrecognized cause of shale instability. In IADC/SPE Drilling Conference. Society of Petroleum Engineers.?

Steiger RP (1982) Fundamentals and use of potassium/polymer drilling fluids to minimize drilling and completion problems associated with hydratable clays. J Petrol Technol 34(08):1661-1670

Talal AL-Bazali, (2013) A novel experimental technique to monitor the time-dependent water and ions uptake when shale interacts with aqueous solutions. Rock Mech Rock Eng 46(5):1145-1156

Talal M AL-Bazali, Jianguo Zhang, Martin E Chenevert and Mukul M Sharma (2006) Factors Controlling the Membrane Efficiency of Shales when Interacting with Water-Based and Oil-Based Muds, SPE 100735, presented at the SPE International Oil and Gas Conference and Exhibition in China, held 5-7, in Beijing, China.

Tao L, Xiao-Feng T, Yu Z, Tao G (2010) Swelling of K+, Na+ and $\mathrm{Ca} 2+-$ montmorillonites and hydration of interlayer cations: a molecular dynamics simulation. Ch Phys B 19(10):109101

Van Oort E (2003) On the Physical and Chemical Stability of Shales. J Petrol Sci Eng 38(3-4):213-235

Yu M, Chenevert ME, Sharma MM (2003) Chemical-mechanical wellbore instability model for shales: accounting for solute diffusion. J Petrol Sci Eng 38(3-4):131-143

Jianguo Zhang, David E. Clark, Talal M. Al-Bazali, Martin E. Chenevert, Juan Carlos Rojas, and Seehong Ong (2006) Ion Movement and Laboratory Technique to Control Wellbore Stability, Presented at the 2006 AADE Fluids Conference, held in Houston, TX on April 11-12.

Zhang S, Sheng JJ, Qiu Z (2016) Maintaining shale stability using polyether amine while preventing polyether amine intercalation. Appl Clay Sci 132:635-640

Publisher's Note Springer Nature remains neutral with regard to jurisdictional claims in published maps and institutional affiliations. 